campus will serve as what Gerry Rubin, Hughes vice-president for research, calls a "research hotel", where teams of visiting scholars, who may or may not be Hughes investigators, can spend time together working on projects of interest. The groups could come "for a few months, or even a couple of years", says Rubin. "No university can hold space open for that."

The facility will be built on a recently acquired 281-acre site. It will house around 24 principal investigators and up to 300 support staff, plus visiting scientists. Hughes has put aside $\$ 500$ million for the project over 10 years, including planning, construction and $\$ 50$ million a year for operations after 2005. A director will be appointed about a year before operations begin.

Hughes officials say that investigators at the campus will not have tenure, although their five-year appointments will be renewable. "We've spent a lot of time discussing how to keep it fresh," says Cech. "We think we can keep people moving in and out of the place."

Cech and Rubin arrived at HHMI at the start of 2000 (see Nature 402, $334-335$; 1999) and have since been working on a new direction for the charity. The announcement is its central component. "This is something that the new leadership group here has cooked up," says Cech.

\title{
Weapons labs escape FBI action
}

\section{Irwin Goodwin, Washington}

Bill Richardson, the US energy secretary in Bill Clinton's administration, spent his last two days in office trying to restore the morale and motivation of thousands of scientists at US nuclear weapons labs.

He announced that, after a seven-month investigation, the FBI will not be bringing criminal charges against any workers at the Los Alamos National Laboratory (LANL) in New Mexico, where two computer hard drives containing secret nuclear-weapons data temporarily went missing last spring.

The FBI "was unable to determine responsibility for the disappearance ... and found no evidence that the classified information contained on the hard drives had been compromised", the energy department said in a statement.

At least four Los Alamos employees had been investigated in connection with the disappearance. Coming close on the heels of the high-profile Wen Ho Lee affair - in which a Taiwan-born computer scientist working at LANL had been accused of passing classified information to China the investigation had seriously shaken the morale of the laboratory's scientists.

Richardson also extended the energy department's contract with the University of California to manage LANL and its sister

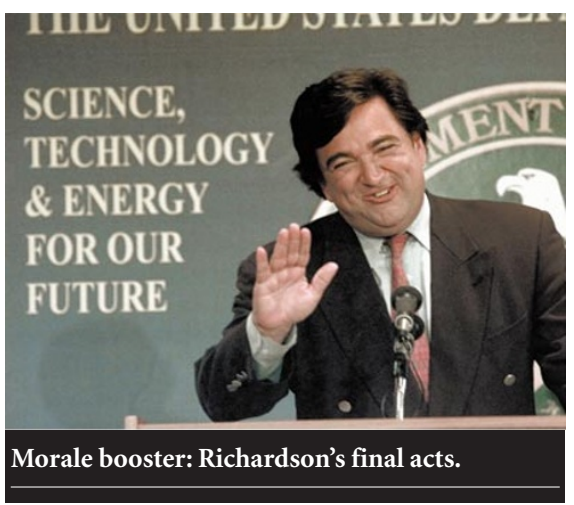

Lawrence Livermore laboratory near San Francisco until September 2005. The university has always managed the weapons labs, but had recently been criticized by Congress and the energy department for allowing apparent security lapses.

In addition, Richardson withdrew the threat of polygraph tests for workers, which he had announced after Wen Ho Lee was sacked nearly two years ago. Initially he wanted 8,000 employees, mostly scientists, to take the test, but reduced this to 400 after many resigned and young researchers refused to accept jobs. "We have great scientists in the weapons labs," Richardson says, "and we have to make sure we can retain and recruit the best and brightest."

\section{Journal will publish accused scientist's work}

\section{Rex Dalton, San Diego}

After months of debate, a leading journal has decided it will consider for publication the research by a renowned geochemist accused of criminal offences unconnected to his work

Geochimica et Cosmochimica Acta has been in turmoil for months after two articles were submitted co-authored by Yale University professor Antonio Lasaga, who has been charged with child sex crimes. Lasaga specializes in the kinetics of geochemical processes.

The Reed Elsevier journal is jointly sponsored by the Geochemical Society and the Meteoritical Society. The journal's editor, Frank Podosek, a professor at Washington University in St Louis, Missouri, decided not to publish research bearing Lasaga's name, saying he wanted to protect the societies and the journal. "I didn't want to create the impression we were looking the other way," Podosek says.

Two other co-authors on the articles Hiroshi Ohmoto of Pennsylvania State University and Andreas Luttge of Rice University in Texas - immediately filed complaints with the journal's publications committee.

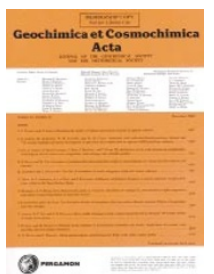

Luttge, an associate professor now seeking tenure at Rice after studying under a German fellowship with Lasaga at Yale, is upset by the publication delay. "I have to feed my family," says Luttge, "and proceed with my career. I spent four years at Yale - I can't throw out that work."

Lasaga and his attorneys declined interview requests. Lasaga has pleaded guilty to two federal felonies for possession of child pornography, but has since attempted to withdraw the pleas. He also faces state charges for alleged sexual abuse of a young boy. $\mathrm{He}$ has pleaded innocent in this case.

As tensions mounted in the geochemical societies over whether to publish the papers, Podosek polled the journal's 55 associate editors on their positions. About two-thirds of those responding supported publication of Lasaga's work, says Podosek. But Podosek stood firm in his view.

A compromise was finally worked out by Geochemical Society president Michael Hochella of Virginia Polytechnical Institute, and the University of Arizona's Michael Drake, the former president of the Meteoritical Society.

Under the arrangement, Podosek will not handle research articles where Lasaga is an author - an associate editor will direct them through the normal peer-review process.

"This has been an extraordinarily difficult situation for all concerned," say Hochella and Drake in a joint statement. "Our societies do not have a mechanism to deal with reviewing papers based on anything other than scientific merit and the standard ethical aspects of scientific research."

At their annual meetings later this year, the societies' boards will consider adopting a policy to "define such a mechanism", the statement says. Meanwhile, Podosek and Lasaga's co-authors were satisfied with the outcome. "They made the right decision," says Ohmoto.

But others were more critical. Nicholas Cozzarelli, a molecular biologist at the University of California and editor of the Proceedings of the National Academy of Sciences, says: "The [Lasaga] papers should be treated like any others. It is a slippery slope when editors make decisions on non-scientific matters." 